\title{
Editorial: The mirage of CRM
}

According to the Gartner group, half of US customer relationship management (CRM) projects and more than 80 per cent of European CRM projects are considered failures. These massive failures have cost millions of dollars per company. What's gone wrong?

The basic idea behind CRM was to collect a great deal of information about customers, prospects, products, promotions and other data, and put them into a giant in-house data warehouse. To access and manipulate the data in the warehouses, very sophisticated software costing at least a million dollars the first year, was installed. There are really two basic goals of CRM:

- build and maintain a relationship with prospects and customers based on knowing lots of relevant information about them, and using the information to guide marketing and sales strategy

- use that information to make the right offer to the right customer at the right time, thereby increasing sales and pleasing the customers.

Achievement of the goals was based on four assumptions, all of which proved to be invalid in practice:

- one-to-one marketing is an achievable goal given the right information and software. Stated another way, customer and prospect purchasing behaviour can be predicted accurately based on information that can be collected about them

- customer and prospect behaviour is heavily influenced by timely and relevant offers

- companies can shift rapidly from being product focused (employee bonus based on the level of sale of particular products) to being customer focused (employee bonus based on the level of sales to particular customer segments, regardless of what products they buy)

- introduction of CRM has a positive return on investment (ROI) by increasing sales and profits by more than its cost.

Let us see why none of these assumptions proved to be correct. In the first place, why do customers and prospects decide to buy anything? Marketers can come up with lots of answers, but the key answer is that they decide that owning the product or service at a particular time will make them happier than not owning them. What happiness consists of is defined by the person who is trying to possess it, and varies from person to person, and from time to time.

I like Big Macs, but not all the time. Sometimes I like fish, sometimes chicken, and quite often I like home cooked vegetables. There is no way that a marketer can accurately predict what I want to eat next, unless they know what I ate last, how hungry I am, where I am 
at the time, who I am with, how much money and time I have available right now for eating. There is no way that any data warehouse could ever collect such timely and relevant information, or that someone besides the customer himself could accurately weigh the importance of each fact.

Besides my eating habits, the same principle applies to predicting my interest in taking a trip, buying clothing, buying a car or an appliance, or taking a college course. Some relevant information can be collected but not enough to make accurate predictions concerning Arthur Hughes today. What can be done with some accuracy, is to say that people in Arthur Hughes' age and income group with a similar occupation, are more likely to buy a certain type of clothing than the average person, picked out at random. But of course, that is not CRM, or one-to-one marketing. That is old-fashioned database marketing where segments are being targeted. A data warehouse is not necessary for that. It needs only a database (that can be built for a fraction of the cost of a warehouse), which permits the customer and prospect base to be divided into purchasing segments.

What is the difference between database marketing and CRM? They are both based on databases of prospects and customers, which are used to guide marketing and sales strategy. CRM requires a large data warehouse with costly software, aimed at determining and influencing the behaviour of an individual through one-to-one marketing. Database marketing is based on a data mart, which costs about 10 per cent of the cost of a CRM warehouse. Database marketing is usually aimed at identifying customer segments and marketing to them, plus building one-to-one relationships with existing customers through loyalty-building communications.
To see the difference, think of 1,000 customers for which there are data. In certain circumstances it might be possible to predict with 90 per cent certainty that 100 of them will buy product $\mathrm{X}$ within the next month. But it cannot be 90 per cent certain that Arthur Hughes (one of the 1,000) will buy the product next month or ever. The first conclusion comes from segment analysis using database marketing. The second conclusion would come from CRM if it could be made to work. Unfortunately, it cannot.

The second assumption is wrong for a similar reason. Does a person eat because they are hungry, or because they have received a timely communication telling them that a particular restaurant was having a special on lobster dinners? Of course, if the person is hungry, enjoys lobster and has the time and money to go to a restaurant right now, the offer would be a wonderful blessing. But the warehouse cannot contain that information. Mass marketing on television showing people eating delicious lobster dinners at a low price can work wonderfully. The image sticks in people's minds and will be recalled the next time they are hungry. A warehouse is not needed to design and place such adverts. Mass marketing works very well and is a lot cheaper in terms of sales per dollar spent.

The third assumption, that companies can rapidly move from being product focused to being customer focused, is the weakest of all. After working with dozens of large American corporations, I can report that it is almost impossible for most companies to become customer focused. Why? Because of the way business is developed. Someone creates a new camera, computer, automobile, or a hotel. The company that develops the product wants to realise a return on their investment. They put a product manager 
in charge of the marketing of it. The manager does everything they can think of: mass marketing, point of purchase displays, retailer subsidies, direct marketing. Of course, if the company has a list of prospects in the warehouse, the manager may try a promotion to that list to see if it works. But the manager's goal is primarily to sell the new product, and only secondarily to increase overall company customer lifetime value.

Could all the product managers be replaced with customer segment managers? Probably not. No company has ever done that, and none ever will. Once a product has been developed, its promotion cannot be left to chance.

No-one will say, 'We will be nice to our customers and hope that they notice our new hotel. We won't specifically promote this new hotel, because one of our older hotels may suit some customers better'.

The final assumption, that CRM will increase sales by more than its cost, is the most costly mistake. CRM (and database marketing) are incremental. The company is already selling products without the CRM. The idea is that it could sell more with the CRM. How much more? 5 per cent, 10 per cent? Few CRM installations increase sales by as much as 5 per cent. Even if the CRM does succeed in increasing sales, it has to overcome the hurdle of millions of dollars spent in the CRM installation and maintenance. The net result is almost always a massive loss of profits.

CRM fails, then, primarily because of flaws in its underlying concepts. A company is better off building an inexpensive marketing database, and using it to build profitable relationships with its customers.

Arthur Middleton Hughes Editorial Board 